\title{
Rating of Perceived Exertion
}

National Cancer Institute

\section{Source}

National Cancer Institute. Rating of Perceived Exertion. NCI Thesaurus. Code C122028.

A scale for a subject to rate their perception of the intensity of their own physical effort. 